\title{
1,8-Naphthalimides for non-doping OLEDs: the tunable emission color from blue, green to red
}

\author{
Jia-An Gan ${ }^{\mathrm{a}}$, Qun Liang Song ${ }^{\mathrm{b}}$, Xiao Yuan Hou ${ }^{\mathrm{b}}$, Kongchang Chen ${ }^{\mathrm{a}}$, He Tian ${ }^{\mathrm{a}, *}$ \\ a Institute of Fine Chemicals, East China University of Science \& Technology, 200237 Shanghai, PR China \\ b Surface Physics Laboratory (National Key Laboratory), Fudan University, 200433 Shanghai, PR China
}

Received 23 April 2003; received in revised form 31 July 2003; accepted 8 September 2003

\begin{abstract}
Substitution at the 4-position of 1,8-naphthalimide with electron-donating groups can increase fluorescent quantum yields and change emissive wavelengths from blue to red. Based on this molecular design concept, novel naphthalimide derivatives containing Schiff base moiety were prepared by condensing 4-hydrazino-1,8-naphthalimides with the aldehydes. Amino conjugation between the 4-amino-1,8naphthalimide and the substituted moiety resulted in red shift of the absorption and fluorescence maximum wavelengths in the acetonitrile solution and in the net solid film. In the meantime, concentration-quenching effect of fluorescence for common luminescent materials was avoided. Some of these dyes emit brilliant red fluorescence in solid films and were used as non-doping emissive materials to fabricate electroluminescence devices. Based on these results, guidelines for the molecular design of non-doping red emissive materials for OLED applications are presented in this paper.
\end{abstract}

(C) 2004 Elsevier B.V. All rights reserved.

Keywords: 1,8-Naphthalimide; Organic light-emitting diodes; Electroluminescence

\section{Introduction}

Full color red-green-blue (RGB) displays based on organic materials own very attractive prospects. Several methods have been developed for obtaining RGB color pixels [1-3]. Since the highest driving efficiency can be achieved by using self-emitting RGB pixels, it is important to develop light emitting materials for each of these colors. Materials for green and blue organic light-emitting diodes (OLEDs) with high luminance, high efficiency, saturated emission, and substantial lifetime have been reported [4-7]. Recently, dot matrix OLED panels with blue and green colors became commercially available and a full color quarter video graphics array $(320 \times 240$ dots $)$ panel was also demonstrated [8]. However, red emissive materials with high fluorescent quantum yields are not as common as blue or green materials in OLED applications [9]. There were only a few organic compounds reported to have red emissions, including pyran-containing compounds [10], europium chelate complexes [11], and porphyrin compounds [12-15]. These dyes possess a highly concentration dependent emission. They have an inherent tendency to crystallize

\footnotetext{
* Corresponding author. Tel.: +86-2164252756; fax: +86-2164252288. E-mail address: tianhe@ecust.edu.cn (H. Tian).
}

and become either weakly emissive or not emissive at all in the solid state. While doping the red emissive materials in a host matrix is the common method for the construction of red OLEDs, concentration quenching, as a result of interaction among molecules at high concentration, is a common and serious problem for molecule-based emissive materials. Though red OLEDs were improved by transferring energy from a short-wavelength emitting material such as small organic molecules [11] and conjugated polymers to europium complexes [14], the concentration quenching cannot be avoided completely. For any red dopant, including the very famous DCM series compounds reported previously except the systems in this work, there is an optimal doping concentration less than $2 \%$ in the host matrix [2(b),4,10]. Improved device performance with doping europium chelates, which exhibit characteristic sharp red emission, also has been demonstrated [16]. Nevertheless, a problem yet to be resolved is the insufficient overlap between the spectral bands of emission of the host matrix and that of absorption of the red dopant. With sensitive emission variation and the need of strict control on doping level, doping is unlikely to be a favored approach in the mass production of OLEDs, which requires high consistency in production quality. On the other hand, the synthetic routes of these red emissive compounds are rather complicated 
[5] and, consequently, result in high production cost for red OLED devices. Therefore, there remains much room and challenge for the synthesis of red emissive materials with high efficiency and color purity. More recently, Chen et al. [17] developed a non-doping red-emissive molecule [(2,3-bis- $N, N$-1-naphthylphenylamino)- $N$-methylmaleimide] with respectable efficiency and brightness.

1,8-Naphthalimide derivatives have photophysical properties, which have been widely used as brilliant yellow dyes in synthetic fiber technology and as optical brightener $[18,19]$, as functional segment for the design of dual-mode chemical (protons)/electrochromic molecular switches [20], and as functional fluorescent imaging polymer. [21,22] Naphthalimide derivatives are also an attractive class of electron-deficient organic materials for OLEDs and are used as a new type of electron-transporting emitting materials for both small molecule and polymer-based OLEDs with high performance, good light stability, high fluorescent quantum yield, and high electron affinity [23,24]. Related naphthalene-tetra carboxylic diimide compounds have electron mobility as high as $0.16 \mathrm{~cm}^{2} /(\mathrm{V} \mathrm{s})[25]$. However, most of the previous work concluded that 1,8-naphthalimides compounds could be utilized for green or blue devices due to the fact that naphthalimide derivatives emit light mainly in the blue and green-yellow regions [26]. Few compounds previous reported have emission wavelengths longer than $600 \mathrm{~nm}$. As hole-blocking and electron-conducting host materials, the 1,8-naphthalimides were best used more recently for red phosphorescent dopant Ir-based complexes [27]. In fact substitution at the 4-position of 1,8-naphthalimide with electron-donating groups can in- crease fluorescent quantum yields and tune easily the emission wavelengths to longer ranges [28-31]. Based on this finding, we prepared several novel naphthalimide derivatives, molecular glass materials, by condensation of 6-hydrazino-benzo-[de]-isoquinoline-1,3-dione with the aldehydes as shown in Scheme 1. The synthetic procedures have more than $80 \%$ yields towards these emitting molecules. Some of them emit brilliant red fluorescence in solid films and the concentration-quenching phenomenon is avoided. Non-doping film of 6-( $N$-anthracenylmethylidenehydrazino)-benzo-[de]-isoquinoline-1,3-dione (NP-RED3) was used as emissive layer to fabricate OLEDs. NP-RED3 has a red emission peak at $620 \mathrm{~nm}$ with a maximum brightness of $15.5 \mathrm{~cd} / \mathrm{m}^{2}$ and a maximum current density of $2.9 \mathrm{~mA} / \mathrm{cm}^{2}$.

\section{Experimental}

\subsection{General}

${ }^{1} \mathrm{H}$ NMR spectra were recorded on a Brucker AM-500 spectrometer. Chemical shifts were given in ppm $(\delta)$, relative to tetramethysilane (TMS). Mass spectra were recorded on an MA1212 instrument using standard conditions (EI, $70 \mathrm{eV}$ ). UV-Vis spectra were recorded on a Varian Cary 500 spectrometer. IR spectra were recorded on a Nicolet FT-IR20SX spectrometer. Photo-luminescent spectra were recorded on Varian Cary Eclipse. Elemental analysis data were obtained on a Perkin-Elmer 240c instrument. Fluorescence lifetimes of compounds were measured by

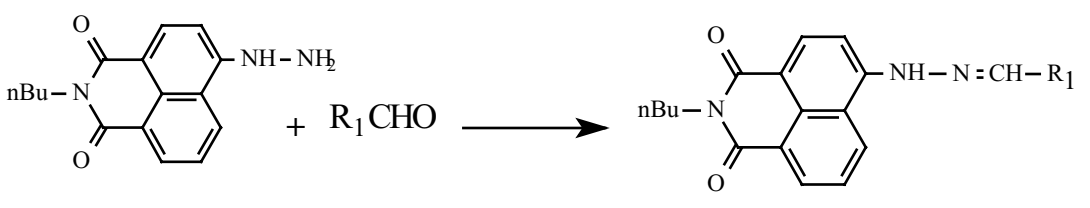

NP-REF: $\quad \mathrm{R}_{1}=\mathrm{CH}_{3}$

NP-RED1: $\mathrm{R}_{1}=$<smiles>Cc1c2ccccc2cc2ccc([18O][Y10]#N)cc12</smiles>

NP-RED2: $\mathrm{R}_{1}=$

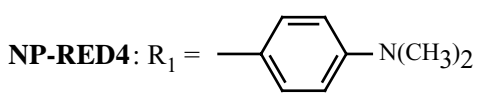

2

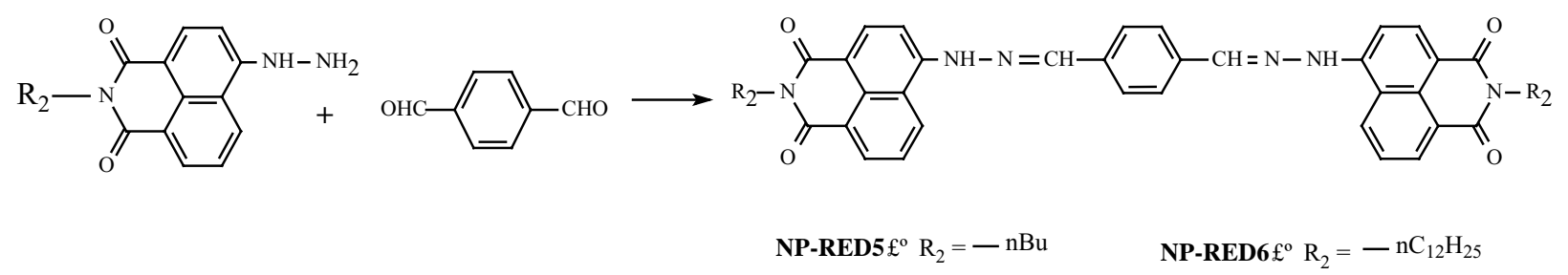

Scheme 1. The synthesis routes of the compounds. 
Table 1

Absorption and fluorescence spectra data of the compounds $\left(\lambda_{\max }^{\mathrm{ab}} / \mathrm{nm}\right.$, $\lambda_{\max }^{\mathrm{fl}} / \mathrm{nm}$ and relative fluorescence quantum yield $\left(\varphi_{\mathrm{f}}\right), 10^{-4} \mathrm{M}$ in $\mathrm{CH}_{3} \mathrm{CN}$ and in the solid state)

\begin{tabular}{llll}
\hline Compounds & $\lambda_{\max }^{\mathrm{ab}}(\log \varepsilon)$ & $\begin{array}{l}\lambda_{\max }^{\mathrm{fl}} \text { in } \\
\mathrm{CH} 3 \mathrm{CN}\left(\varphi_{\mathrm{f}}\right)^{\mathrm{a}}\end{array}$ & $\begin{array}{l}\lambda_{\max }^{\mathrm{fl}} \text { in the } \\
\text { solid state }\end{array}$ \\
\hline NP-REF & $431.4(4.29)$ & $521(0.90)$ & 545 \\
NP-RED1 & $441.0(4.36)$ & $527(0.62)$ & 558 \\
NP-RED2 & $453.4(4.31)$ & $546(0.23)$ & 643 \\
NP-RED3 & $464.4(4.42)$ & $565(0.14)$ & 661 \\
NP-RED4 & $477.0(4.42)$ & $659(0.024)$ & - \\
NP-RED5 & $485.2(4.80)$ & $536(0.95)$ & 618 \\
NP-RED6 & $486.3(4.78)$ & $517(0.96)$ & 620 \\
niH [35] & & $379(0.03)$ & \\
NP-OCH $[36]$ & & 480 & \\
NP-piperazin [20] & & $515(0.03)$ & \\
NP-N $\left(\mathrm{CH}_{3}\right)_{2}[23]$ & & 538 & \\
\hline
\end{tabular}

${ }^{\text {a }}$ Rhodamine $\mathrm{B}$ in $\mathrm{CH}_{3} \mathrm{CN}$ was used as fluorescence quantum yields standard and was defined as 1 . NP-REF was prepared by condensation of 2-butyl-6-hydrazino-benzo-[de]-isoquinoline-1,3-dione with acetaldehyde [20]. NiH: 1,8-naphthalimide [35]; $\mathrm{NP}^{-\mathrm{OCH}_{3}}$ : 4-methyoxyl- $N$ butyl-1,8-naphthalimide [36]; NP-piperazin: 4-(4'-methyl-piperazin-1-yl)$\mathrm{N}$-butyl-1,8-naphthalimide [20]; $\mathrm{NP}-\mathrm{N}\left(\mathrm{CH}_{3}\right)_{2}$ : 4-dimethylamino- $\mathrm{N}$ butyl-1,8-naphthalimide [23].

single-photon counting technique (Edinburgh FL 900) with a hydrogen-filled flash lamp or a nitrogen lamp as the excitation source. Data were analyzed using a non-linear least-squares fitting program with deconvolution method. The temporal resolution after deconvolution of the exciting pulse was $\sim 200 \mathrm{ps}$. The absorption and fluorescence spectra data of the compounds in the solution and in the solid film are shown in Table 1.

\subsection{Syntheses}

All the compounds were derived from 2-butyl- or 2-dodecyl-6-hydrazino-benzo-[de]-isoquinoline-1,3-diones which were previously reported [20]. General process of preparing NP-RED1-4: $1 \mathrm{~g}$ (3.5 mmol) 2-butyl-6-hydrazinobenzo-[de]-isoquinoline-1,3-dione (BHBI) and $3.6 \mathrm{mmol}$ of the aldehyde were added with stirring into $60 \mathrm{ml}$ of ethanol, and refluxed for $2.5 \mathrm{~h}$. After cooling to room temperature, the precipitated product was filtered and dried.

NP-RED1: from BHBI/benzaldehyde, recrystallization from ethanol to afford yellow crystals with a yield of 85\%, m.p.: 204-206 ${ }^{\circ} \mathrm{C}$. MS-EI: $371\left(M^{+}\right) .{ }^{1} \mathrm{H}$ NMR (in DMSO-d 6 ) $\delta(\mathrm{ppm}): 8.79(\mathrm{~d}, J=8.36 \mathrm{~Hz}, 1 \mathrm{H}), 8.48(\mathrm{~d}$, $J=6.72 \mathrm{~Hz}, 1 \mathrm{H}), 8.46(\mathrm{~s}, 2 \mathrm{H}), 8.38(\mathrm{~d}, J=8.49 \mathrm{~Hz}$, $1 \mathrm{H}), 7.81(\mathrm{~m}, 3 \mathrm{H}), 7.75(\mathrm{~d}, J=8.13 \mathrm{~Hz}, 1 \mathrm{H}), 7.50-7.42$ $(\mathrm{m}, 3 \mathrm{H}), 4.03\left(\mathrm{t}, \mathrm{NCH}_{2}-, 2 \mathrm{H}\right), 1.60\left(\mathrm{~m},-\mathrm{CH}_{2}-, 2 \mathrm{H}\right), 1.35$ $\left(\mathrm{m},-\mathrm{CH}_{2}-, 2 \mathrm{H}\right), 0.93\left(\mathrm{t},-\mathrm{CH}_{3}, 3 \mathrm{H}\right)$. Element analysis: Calc. for $\mathrm{C}_{23} \mathrm{H}_{21} \mathrm{~N}_{3} \mathrm{O}_{2}$ : C 74.39, H 5.66, N 11.32; Found: C 74.30, H 5.62, N 11.28\%.

NP-RED2: from BHBI/4-methoxybenzaldehyde, recrystallization from ethanol/acetone $(1: 1)$ to afford red powder with a yield of $87 \%$, m.p.: $215-216^{\circ} \mathrm{C}$. MS-EI: $401\left(M^{+}\right)$. ${ }^{1} \mathrm{H}$ NMR (in DMSO-d 6 ) $\delta(\mathrm{ppm}): 8.79(\mathrm{~d}, J=8.37 \mathrm{~Hz}$, $1 \mathrm{H}), 8.48$ (d, $J=7.22 \mathrm{~Hz}, 1 \mathrm{H}), 8.42$ (s, 2H), 8.37 (d, $J=$
$8.53 \mathrm{~Hz}, 1 \mathrm{H}), 7.78(\mathrm{~m}, 3 \mathrm{H}), 7.70(\mathrm{~d}, J=4.58 \mathrm{~Hz}, 1 \mathrm{H}), 7.05$ $(\mathrm{d}, J=8.75 \mathrm{~Hz}, 2 \mathrm{H}), 4.03\left(\mathrm{t}, \mathrm{NCH}_{2}-, 2 \mathrm{H}\right), 3.83\left(\mathrm{~s}, \mathrm{OCH}_{3}\right.$, $3 \mathrm{H}), 1.60\left(\mathrm{~m},-\mathrm{CH}_{2}-, 2 \mathrm{H}\right), 1.35\left(\mathrm{~m},-\mathrm{CH}_{2}-, 2 \mathrm{H}\right), 0.93(\mathrm{t}$, $\left.-\mathrm{CH}_{3}, 3 \mathrm{H}\right)$. Element analysis: Calc. for $\mathrm{C}_{24} \mathrm{H}_{23} \mathrm{~N}_{3} \mathrm{O}_{3}: \mathrm{C}$ 71.82, H 5.74, N 10.47; Found: C 71.73, H 5.72, N 10.42\%.

NP-RED3: from BHBI/9-anthraldehyde, recrystallization from ethanol/acetone (1:2) to afford red crystals with a yield of $83 \%$, m.p.: $238-240{ }^{\circ} \mathrm{C}$. MS-EI: $471\left(M^{+}\right)$. ${ }^{1} \mathrm{H}$ NMR (in DMSO-d 6 ) $\delta(\mathrm{ppm}): 9.72(\mathrm{~s}, 1 \mathrm{H}), 8.89(\mathrm{~d}, J=8.42 \mathrm{~Hz}$, $1 \mathrm{H}), 8.84(\mathrm{~d}, J=8.42 \mathrm{~Hz}, 2 \mathrm{H}), 8.70(\mathrm{~s}, 1 \mathrm{H}), 8.54(\mathrm{~d}$, $J=7.18 \mathrm{~Hz}, 1 \mathrm{H}), 8.44(\mathrm{~d}, J=8.46 \mathrm{~Hz}, 1 \mathrm{H}), 8.20(\mathrm{~d}$, $J=8.47 \mathrm{~Hz}, 2 \mathrm{H}), 7.89(\mathrm{t}, J=7.70 \mathrm{~Hz}, J=8.00 \mathrm{~Hz}$, $1 \mathrm{H}), 7.73(\mathrm{~m}, 3 \mathrm{H}), 7.62(\mathrm{t}, J=7.57 \mathrm{~Hz}, J=7.36 \mathrm{~Hz}$, $2 \mathrm{H}), 4.05\left(\mathrm{t}, \mathrm{NCH}_{2}-, 2 \mathrm{H}\right), 1.62\left(\mathrm{~m},-\mathrm{CH}_{2}-, 2 \mathrm{H}\right), 1.36(\mathrm{~m}$, $\left.-\mathrm{CH}_{2}-, 2 \mathrm{H}\right), 0.93\left(\mathrm{t},-\mathrm{CH}_{3}, 3 \mathrm{H}\right)$. Element analysis: Calc. for $\mathrm{C}_{31} \mathrm{H}_{25} \mathrm{~N}_{3} \mathrm{O}_{2}$ : C 78.98, H 5.31, N 8.92; Found: C 78.88, H 5.29, N 8.89\%.

NP-RED4: from BHBI/4-dimethylaminobenzaldehyde, recrystallization from ethanol/acetone (2:1) to afford red-brown crystals with a yield of $78 \%$, m.p.: $267-269^{\circ} \mathrm{C}$. MS-EI: $414\left(M^{+}\right) .{ }^{1} \mathrm{H}$ NMR (in DMSO-d 6 ) $\delta$ (ppm): 8.79 $(\mathrm{d}, J=8.47 \mathrm{~Hz}, 1 \mathrm{H}), 8.47(\mathrm{~d}, J=7.26 \mathrm{~Hz}, 1 \mathrm{H}), 8.36$ $(\mathrm{t}, J=4.29 \mathrm{~Hz}, J=4.23 \mathrm{~Hz}, 2 \mathrm{H}), 7.77(\mathrm{t}, J=8.26$, $J=7.47 \mathrm{~Hz} 1 \mathrm{H}), 7.65(\mathrm{dd}, J=8.54, J=8.85 \mathrm{~Hz}, 3 \mathrm{H})$, $6.79(\mathrm{~d}, J=8.9 \mathrm{~Hz}, 2 \mathrm{H}), 4.03\left(\mathrm{t}, \mathrm{NCH}_{2}-, 2 \mathrm{H}\right), 3.00(\mathrm{~s}, 6 \mathrm{H})$, $1.60\left(\mathrm{~m},-\mathrm{CH}_{2-}, 2 \mathrm{H}\right), 1.35\left(\mathrm{~m},-\mathrm{CH}_{2}-, 2 \mathrm{H}\right), 0.93\left(\mathrm{t},-\mathrm{CH}_{3}\right.$, $3 \mathrm{H})$. Element analysis: Calc. for $\mathrm{C}_{25} \mathrm{H}_{26} \mathrm{~N}_{4} \mathrm{O}_{2}$ : C 72.46, $\mathrm{H}$ 6.28, N 13.53; Found: C 72.36, H 6.25, N 13.48\%.

General preparation process for NP-RED 5 and NP-RED 6: $7 \mathrm{mmol}$ BHBI or DHBI and $3.4 \mathrm{mmol}$ terephthalaldehyde were added with stirring into $60 \mathrm{~mL}$ of ethanol and refluxed for $5 \mathrm{~h}$. After cooling to room temperature, the precipitated product was filtered and dried; recrystallization from dimethylformamide afforded the pure product.

NP-RED5: red powder, yield 81\%, m.p. $>300{ }^{\circ} \mathrm{C}$. MS-EI: $664\left(M^{+}\right) .{ }^{1} \mathrm{H}$ NMR (in DMSO-d 6 ) $\delta$ (ppm): 8.85 $(\mathrm{d}, J=7.78 \mathrm{~Hz}, 2 \mathrm{H}), 8.52(\mathrm{~d}, J=6.82 \mathrm{~Hz}, 4 \mathrm{H}), 7.95(\mathrm{~s}$, $4 \mathrm{H}), 7.93(\mathrm{~s}, 2 \mathrm{H}), 7.83(\mathrm{~m}, 4 \mathrm{H}), 4.05\left(\mathrm{t}, \mathrm{NCH}_{2}-, 4 \mathrm{H}\right), 1.60$ $\left(\mathrm{m},-\mathrm{CH}_{2}-, 4 \mathrm{H}\right), 1.36\left(\mathrm{~m},-\mathrm{CH}_{2}-, 4 \mathrm{H}\right), 0.93\left(\mathrm{t},-\mathrm{CH}_{3}, 6 \mathrm{H}\right)$. Element analysis: Calc. for $\mathrm{C}_{40} \mathrm{H}_{36} \mathrm{~N}_{6} \mathrm{O}_{4}$ : C 72.29, H 5.42, N 12.65; Found: C 72.16, H 5.40, N $12.61 \%$.

NP-RED6: red powder, yield 83\%, m.p. > $300^{\circ} \mathrm{C}$. MS-EI: $888\left(M^{+}\right)$. IR (KBr): 3460, 3280, 2950, 2930, 2870, 1690, 1640, 1570, 1430, 1390, 1360, 1270, 1240, 1120, 1100, 940, 780, $760 \mathrm{~cm}^{-1} .{ }^{1} \mathrm{H}$ NMR (in DMSO-d 6 ) $\delta$ (ppm): $8.84(\mathrm{~d}, J=7.78 \mathrm{~Hz}, 2 \mathrm{H}), 8.51(\mathrm{~d}, J=6.82 \mathrm{~Hz}$, $4 \mathrm{H}), 7.95(\mathrm{~s}, 4 \mathrm{H}), 7.93(\mathrm{~s}, 2 \mathrm{H}), 7.73(\mathrm{~m}, 4 \mathrm{H}), 4.05(\mathrm{t}$, $\left.\mathrm{NCH}_{2}-, 4 \mathrm{H}\right), 1.59-1.36(\mathrm{~m}, 40 \mathrm{H}), 0.93\left(\mathrm{t},-\mathrm{CH}_{3}, 6 \mathrm{H}\right)$. Element analysis: Calc. for $\mathrm{C}_{56} \mathrm{H}_{68} \mathrm{~N}_{6} \mathrm{O}_{4}$ : C 75.68, $\mathrm{H} 7.66, \mathrm{~N}$ 9.46; Found: C 75.60, H 7.62, N 9.41\%.

\subsection{Preparation of OLED devices}

NP-RED2, NP-RED5 and NP-RED6 have broad emission spectra. Significant portion of their emission spectral wavelength are below $600 \mathrm{~nm}$, and these compounds 
cannot emit a pure red color. NP-RED3 thick film has a photoemission peak at $661 \mathrm{~nm}$ without emission spectra below $600 \mathrm{~nm}$. Therefore, NP-RED3 was used in the fabrication of OLED devices. The ITO-coated glass substrate was cleaned by repeated ultrasonic wash and oxygen plasma treatment. Organic materials were sequentially deposited onto the ITO substrate with a deposition rate of $0.1-0.2 \mathrm{~nm} / \mathrm{sec}$ at a pressure of $5 \times 10^{-5}$ Torr to form the desired device configuration. The pressure during deposition of aluminum was below $1 \times 10^{-7}$ Torr. $I-V$ and $L-V$ characteristics were measured with computer-controlled source meter Keithley 236 and Si-photodiode calibrated by integrating sphere. EL spectra were recorded on Oriel CCD spectrograph. The emission area of the device was $0.12 \mathrm{~cm}^{2}$, defined by the overlapping area of the anode and the cathode.

\section{Results and discussion}

It is believed that the development of color in 1,8naphthalimides is dependent on the presence of a strong electron-donating substitute on the 4-position of the naphthalimide ring [28-31]. When hydrogen is replaced by an electron-donating group such as an amino group, the fluorescent quantum yield is gradually increased and the emission wavelength is red-shifted from blue to green region. Without extending the conjugation through electron-donating groups, naphthalimide moiety alone does not show red emission. Different color emission was found among azomethine derivatives of 4-amino- $N$-phenylnaphthalimide, in which the $\mathrm{CH}=\mathrm{N}$ group forms part of the common conjugation chain linking $N$-phenylnaphthalimide and a benzene ring [32]. They luminance is present not only in crystals and frozen solutions like azomethines of simpler structures with intramolecular hydrogen bonding, but also in solutions at room temperatures. By altering the structure of the substitute on the benzene ring, one can shift the luminescence in DMF ranging from 465 to $525 \mathrm{~nm}$ and in crystals ranging from 512 to $605 \mathrm{~nm}$ [32].

In our previous design of ferrocene-naphthalimide dyads [20], 6-hydrazino-benzo-[de]-isoquinoline-1,3-dione was condensed with ferrocene formaldehyde to afford 6-( $N$-ferrocenylmethylidene-hydrazino)-benzo-[de]-isoquinoline-1,3-dione. From the molecular structure of these dyes, the naphthalimide moiety and the $\mathrm{CH}=\mathrm{N}$ group are linked by two saturated bonds (structure I in Scheme 2). It seems that the two parts do not conjugate with each other. This may be attributed to the "amino conjugation effect" in the delocalization structures II and III in Scheme 2. The same phenomenon was observed in trans-4-amino-stilbene as described by Jye-Shane Yang et al. [33]. In this case, the whole molecule has a new characteristic in the absorption and emission spectra [34]. The luminescence intensity is determined by the degree of conjugation along the entire molecule and increases with the donor-accepter interaction of the substituents [32]. By replacing the ferrocene unit with suitable substitutes, a series of red fluorescent molecules were successfully prepared. The absorption spectra and fluorescence emission data of the compounds studied in this work are listed in Table 1.

The 4-amino-1,8-naphthalimide part in the de-localized structures above is an intramolecular charge-transfer analog, which typically consists of two parts, an amino substitute electron donor and a naphthalimide electron acceptor. The fluorescence lifetimes of the emitters depend on the electron donor substitutes linked by the $\mathrm{N}=\mathrm{C}$ group. NP-REF was used as a reference compound, which has the simplest methyl group at the termini. The fluorescence emissions of the compounds in this study decay according to single exponential kinetics. By extending the whole amino conjugation length, the fluorescent lifetimes of NP-RED1 and NP-RED3 in THF decrease to 4.71 and $0.29 \mathrm{~ns}$, respectively, in comparison with NP-REF. Similar trend was also evident with NP-RED2 and NP-RED4. The quenching of the excited state in NP-RED2 and NP-RED4 may be attributed to the increase in the electron-donating ability of the substitutes in the para position of the benzene ring. The intramolecular charge transfer and the amino conjugation effect in these compounds will also depend upon polarity of the solvents, which could be also explained by the resonance structures of the compounds shown in Scheme 2. However, this explanation might not be suitable for compound NP-RED5 and

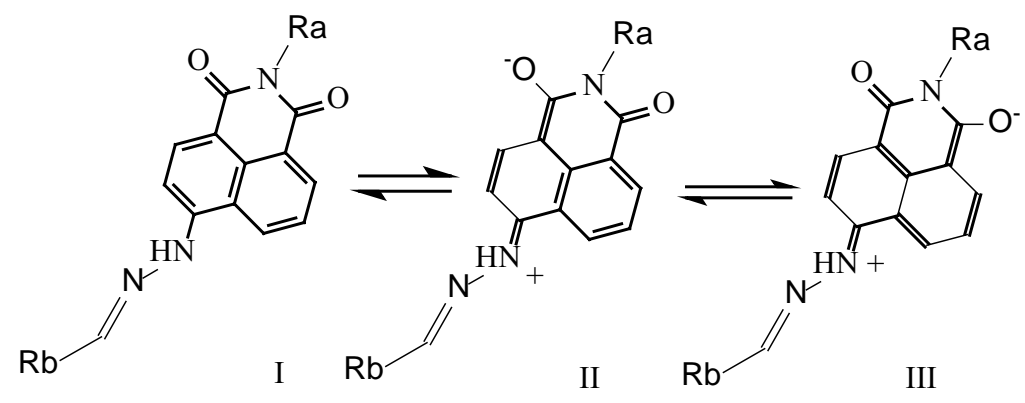

Ra: alkyl chain $\quad R b$ : sustituted aromatic ring

Scheme 2. Resonance structures of the azomethines-substituted 1,8-naphthalimides. 
Table 2

Fluorescent lifetimes of compounds in this study with a single-exponential fits

\begin{tabular}{llllll}
\hline Compounds & $\begin{array}{l}\tau(\mathrm{ns}) \text { in } \\
\mathrm{THF}\end{array}$ & $\begin{array}{l}\tau(\mathrm{ns}) \text { in } \\
\mathrm{C}_{6} \mathrm{H}_{12}\end{array}$ & $\begin{array}{l}\tau(\mathrm{ns}) \text { in } \\
\mathrm{CH}_{3} \mathrm{OH}\end{array}$ & $\begin{array}{l}\tau(\mathrm{ns}) \text { in } \\
\mathrm{CH}_{3} \mathrm{CN}\end{array}$ & $\begin{array}{l}\tau(\mathrm{ns}) \text { in } \\
\text { DMSO }\end{array}$ \\
\hline NP-REF & 7.40 & - & - & 8.14 & - \\
NP-RED1 & 4.71 & 2.72 & 2.24 & 5.29 & 4.37 \\
NP-RED2 & 4.21 & 3.20 & 0.21 & 1.16 & 1.02 \\
NP-RED3 & 0.29 & 0.24 & 0.17 & 0.22 & 0.56 \\
NP-RED4 & 0.23 & 3.08 & - & - & - \\
NP-RED5 & 1.91 & 0.82 & 0.47 & 1.61 & 1.02 \\
NP-RED6 & 1.94 & 1.47 & 1.86 & 1.75 & 0.36 \\
\hline
\end{tabular}

NP-RED6 due to the fact that they consist of two naphthalimide moieties with a tail-to-tail configuration. Our previous study on the naphthalimide dyads with a head-to-head configuration exhibited the complicated intramolecular interaction in such structures [23(d)]. The fluorescent lifetime data in various solvents are listed in Table 2.

In reference to NP-REF, as seen in Table 1, the maximum absorption wavelengths of NP-RED 1-6 in acetonitrile were red-shifted 10, 22, 33, 46, 54, and $55 \mathrm{~nm}$, respectively. This may also be assigned to the lengthening of the conjugated system containing 4-amino-1,8-naphthalimide moiety and increases in the electron-donating abilities of the substitutes. The structural factor determines the luminescence properties of these dyes. NP-RED 1-6 molecules are not as rigid as 1,8-naphthalimide, the naphthalimide part and the azomethine part may not be at the same molecular panel, and the two parts may not form perfect "amino-conjugation" with each other. So the fluorescence of NP-RED 1-6 in the acetonitrile solution $\left(10^{-4} \mathrm{M}\right)$ is still yellow or green in color. In the solid film where the molecule is fixed, red shift of the maximum emission wavelengths of the compounds can be observed much more clearly (Table 1, Figs. 1 and 2). Since there is no electron-donating substitute on the benzene ring of NP-RED1, the conjugated structure of NP-RED1 shifts its maximum emission wavelength to $558 \mathrm{~nm}$, which is still yellow in color. The maximum emission wavelengths of solid

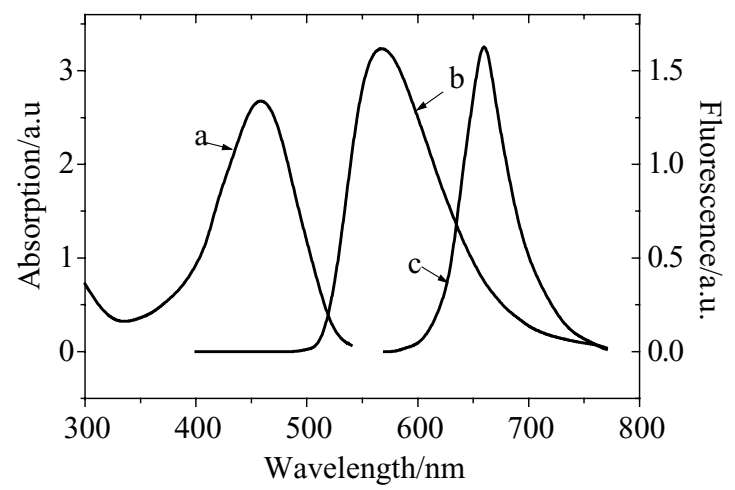

Fig. 1. Absorption and fluorescence spectra of NP-RED3 in acetonitrile $\left(10^{-4} \mathrm{M}\right)$ and in the solid state - curve (a): absorption in acetonitrile; curve (b): fluorescence in acetonitrile; curve (c): fluorescence in the solid film (thickness $>1000 \mathrm{~nm}$ ).

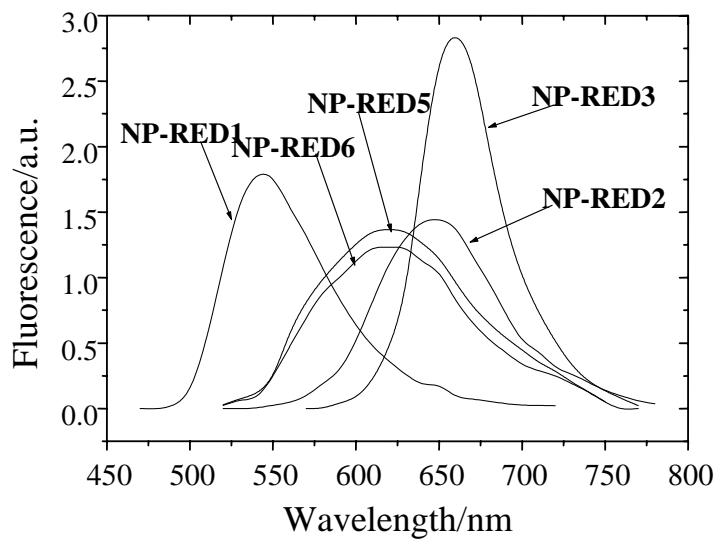

Fig. 2. Fluorescent spectra of NP-RED1-6 in the film (thickness > $1000 \mathrm{~nm}$ ).

NP-RED 2-6 shift to longer wavelengths, emitting brilliant red fluorescence in the solid film (Figs. 1 and 2). The increase in the electron-donating abilities of the substitutes on the para position of the benzene ring is accompanied by large shifts in the luminescence spectra. With a methoxyl group attached to the para position of the benzene ring, the maximum wavelength of solid NP-RED2 shifts to $643 \mathrm{~nm}$. NP-RED4 has a dimethylamino group-a strong electron donor-attached to the para position of the benzene ring. The maximum wavelength of NP-RED4 in acetonitrile shifts to $658 \mathrm{~nm}$. The fluorescence of NP-RED4 in the film was rosy in color as seen by naked eyes. However, the emission is in the far-infrared region and was too weak to be recorded by fluorescence spectrometer in our laboratory. Nevertheless, the rotation of the dimethylamino group may quench single excited state of NP-RED4 as in DCM [5]. When the (para- $N, N^{\prime}$-dimethylamino)-benzenyl group is replaced by a rigid group such as julolidine, the fluorescence of the red emitter will be recovered as that in DCM2 [5]. The corresponding synthesis is in progress. Doubling the degree of amino-conjugation chain along the entire molecule may also result in red shifts of the luminescence spectra as seen in solid NP-RED 5 and 6.

Electronic interaction between the anthracene unit and the 4-amino-1,8-naphthalimide moiety of NP-RED3 is evident in Table 1 and Fig. 1. For NP-RED3, the typical emission bands $(400-460 \mathrm{~nm})$ of anthracene unit disappeared (excited at $350 \mathrm{~nm}$ ). There is only one emission band between $300-800 \mathrm{~nm}$ in acetonitrile $\left(10^{-4} \mathrm{M}\right)$, and the shape is similar to the band of 4-amino-1,8-naphthalimide, which is assigned to the new conjugated system composed of 4-amino-1,8-naphthalimide and the anthracene moiety. This indicates that there exists an intramolecular effective energy transfer from the anthracene moiety to the 4-amino-1,8-naphthalimide in NP-RED3. The results are in satisfactory agreement with the "amino conjugation" theory [33]. In addition, anthracene is a typical electron donor. The photo-induced electron transfer (PET) from the anthracene 
Table 3

Comparison photophysical data for 1,8-naphthalimide compounds

\begin{tabular}{|c|c|c|c|c|c|c|c|}
\hline & \multirow[t]{2}{*}{$\phi_{\mathrm{f}}(\%)$} & \multicolumn{2}{|l|}{$\lambda_{\mathrm{em}}(\mathrm{nm})$} & \multirow[t]{2}{*}{$\lambda_{\mathrm{EL}}(\mathrm{nm})$} & \multirow[t]{2}{*}{$E_{\text {red }}(\mathrm{V})(\mathrm{vs} \mathrm{SCE})$} & \multirow[t]{2}{*}{ EL color } & \multirow[t]{2}{*}{ Reference } \\
\hline & & In $\mathrm{CH}_{3} \mathrm{CN}$ & Solid Film & & & & \\
\hline NP-RED 3 & 14 & 565 & 661 & 620 & -0.76 & Red-orange & This work \\
\hline NP-RED 4 & 2.4 & 659 & $>750$ & & -0.70 & & This work \\
\hline $\mathrm{NP}-\mathrm{N}\left(\mathrm{CH}_{3}\right)_{2}$ & 49 & 515 & & 532 & -1.10 & Green & {$[23(\mathrm{e}), 23(\mathrm{~h})]$} \\
\hline $\mathrm{niH}$ & 3 & 379 & & $400-420$ & -1.25 & Blue & {$[26(b), 26(c)]$} \\
\hline
\end{tabular}

unit to the 1,8-naphthalimide moiety takes place in the same direction as that of intramolecular energy transfer from the anthracene unit to the 1,8-naphthalimide moiety [30]. Both processes red-shift the emission wavelength of NP-RED 3 to longer wavelength region. Consequently, fluorescence lifetime of NP-RED 3 is shortened considerably over that of the reference compound NP-REF (Table 2). When in solutions, all the compounds discussed above, except for NP-RED4, showed similar emission spectra with small wavelength shifts compared to NP-REF. However, when they form solid films, the emissions of these molecular materials are very different from that of NP-REF. For example, the emission of NP-RED3 in the film has a red-shift of more than $110 \mathrm{~nm}$ compared to that of NP-REF. This is apparently related to steric configuration of anthracene unit. This configuration is also favorable in applications like OLEDs [3(b)]. The opto-electronic equipment has to be designed to accept temperature excursions as high as $80^{\circ} \mathrm{C}$. This is a problem since the glass transition temperature or recrystallization temperatures of many organic materials are in range [3(b)]. Materials having high glass transition temperatures are particularly desirable for enhancing the stability and lifetime of the devices. In fact, no distinct glass transition state was observed when compound NP-RED3 was taken on the second heating cycle DSC analysis (differential scanning calorimeter TA DSC 2910 Instrument, not shown in figure), while NP-REF has a $T_{\mathrm{g}}$ of about $115^{\circ} \mathrm{C}$. Thermal analysis results therefore indicated that the target compound has high $T_{\mathrm{g}}$ and good thermal stability, which is very essential for fabricating stable organic EL devices.

Data shown in Tables 1 and 3 also indicate that the emission color of the 1,8-naphthalimides can easily be tuned by using different substitutes at the 4-position [28-31]. Using different 1,8-naphthalimides, OLEDs with blue, green or even orange emission colors have been made, in which the 1,8-naphthalimides acted as non-doping emitter or host matrix with electron- transporting and hole-blocking functions $[23,24,36,37]$. The energy gaps of 1,8 -naphthalimides could also be tuned by chemical modification of their structures, especially by substitution at the 4-position. They have low reduction potentials (about $-1.1 \mathrm{~V}$ versus SCE) [38] and high photostability [18], making them good candidates for use as n-type materials in OLEDs. None of the naphthalimide compounds have a detectable oxidation wave in acetonitrile and dichloromethane, putting it outside of the window available in these solvents (up to 2.0 V) [27]. The HOMO levels for 1,8-naphthalimides are very deep in general (from 7.3 to $6.9 \mathrm{eV}$ ), suggesting that these materials make good blocking layers in OLEDs. The substitution by azomethine unit at the 4-position of $N$-butyl-1,8-naphthalimide reported herein changes the HOMO level of the compound to $6.5 \mathrm{eV}$ (based on the data of the electrochemical measurements) and tunes the energy band gap of the compound as well.

The amorphous state also influences the emission wavelength of these compounds. As seen in Fig. 2, NP-RED2, NP-RED3, NP-RED5 and NP-RED6 in films of more than $1000 \mathrm{~nm}$ have orange-red emission around $620 \mathrm{~nm}$. However, NP-RED2, NP-RED5 and NP-RED6 have broad emission spectra. Significant portions of their emission spectral wavelengths are below $600 \mathrm{~nm}$. These compounds cannot emit pure red color. Because of light scattering effect, the absorption and transmittance spectra of the thick film (>1000 nm) of NP-RED3 cannot be obtained even using the integrated technique. The insert figure of Fig. 3 was absorption spectrum of NP-RED3 vacuum deposition film in $100 \mathrm{~nm}$, which shows that non-aggregation was observed in the film. Thick film of NP-RED3 has a photoemission peak at $661 \mathrm{~nm}$ and no emission spectra below $600 \mathrm{~nm}$. Therefore, it can be used as a non-doping red emitter to fabricate red OLEDs since that the concentration quenching effect is avoid. To keep the injection balance of electron and hole, phthalocyanine copper $(\mathrm{CuPc})$ was used as hole-transporting layer. OLEDs with the structure ITO/CuPc $(12 \mathrm{~nm}) / N, N^{\prime}$-bis(1-naphthyl)- $N, N^{\prime}$-diphenyl-1,1'-biphenyl4,4'-diamine (NPB $30 \mathrm{~nm}$ )/NP-RED3/sodium stearate $(2 \mathrm{~nm}) / \mathrm{Al}(100 \mathrm{~nm})$ were prepared. Better result was obtained with a device where the emitter layer thickness was $10-45 \mathrm{~nm}$. The PL and EL spectra of the material are shown in Figs. 3 and 4, respectively. Luminescence-current density-voltage characteristics of the device are shown in Fig. 5. According to the photoemission results of NP-RED3 (Table 1, Figs. 2 and 3), the emission peak of NP-RED3 film shifts to longer wavelength region with increasing thickness of the film. The device with a $45 \mathrm{~nm}$ thick NP-RED 3 film has double EL peaks at 575 and $620 \mathrm{~nm}$ respectively with a maximum luminance of $15.5 \mathrm{~cd} / \mathrm{m}^{2}$ and a maximum current density of $2.9 \mathrm{~mA} / \mathrm{cm}^{2}$ at an applied voltage of $22 \mathrm{~V}$, shown in Fig. 5. Turn-on voltage of this EL device is $14 \mathrm{~V}$. Unfortunately, other devices with thicker emitting layer (more than $45 \mathrm{~nm}$ ) have much higher turn-on voltage, and the emitting layers were penetrated after the turn on. The above results suggest that the electron-hole recombination process in 


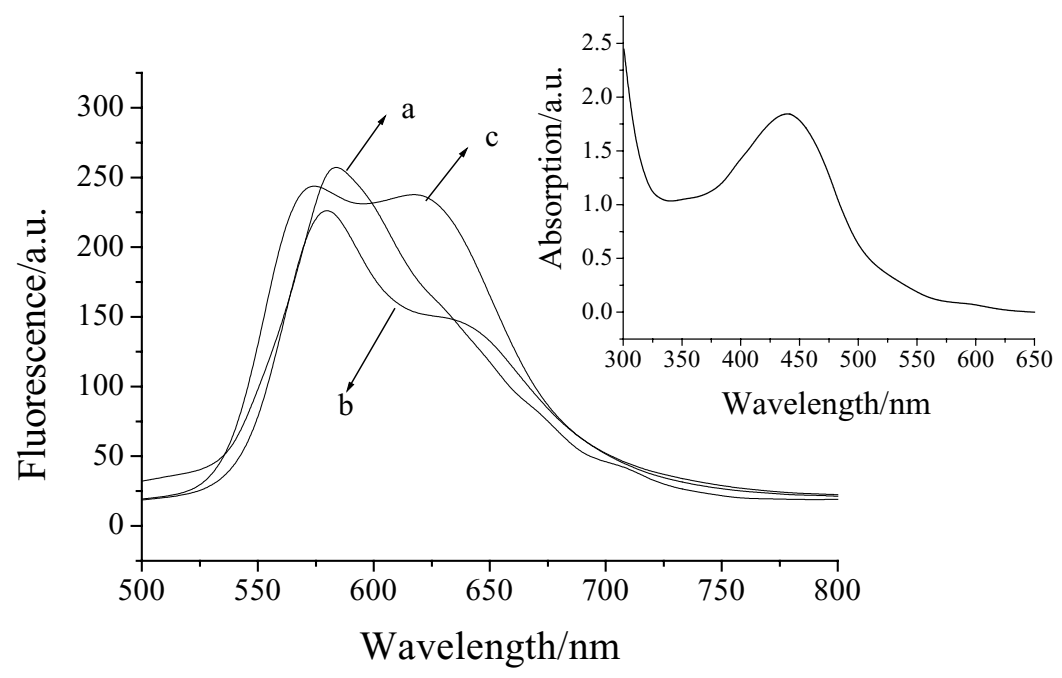

Fig. 3. Fluorescent spectra of NP-RED3 in solid film with the varied thicknesses (a: $8.5 \mathrm{~nm}, \mathrm{~b}: 45 \mathrm{~nm}$, c: $100 \mathrm{~nm}$ ). Inset: The absorption spectra of NP-RED3 in solid film of $100 \mathrm{~nm}$.

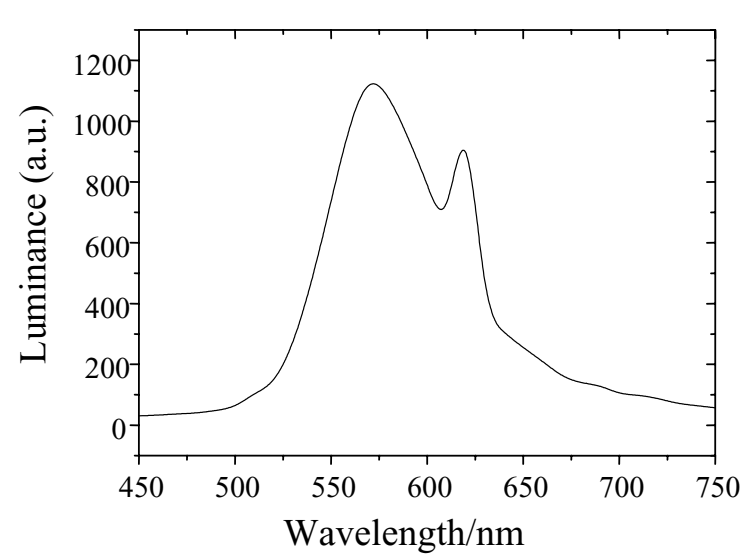

Fig. 4. EL spectra of the device: ITO/CuPc $(12 \mathrm{~nm}) / \mathrm{NPB}(30 \mathrm{~nm}) / \mathrm{NP}-$ RED3 $(45 \mathrm{~nm}) /$ sodium stearate $(2 \mathrm{~nm}) / \mathrm{Al}(100 \mathrm{~nm})$.

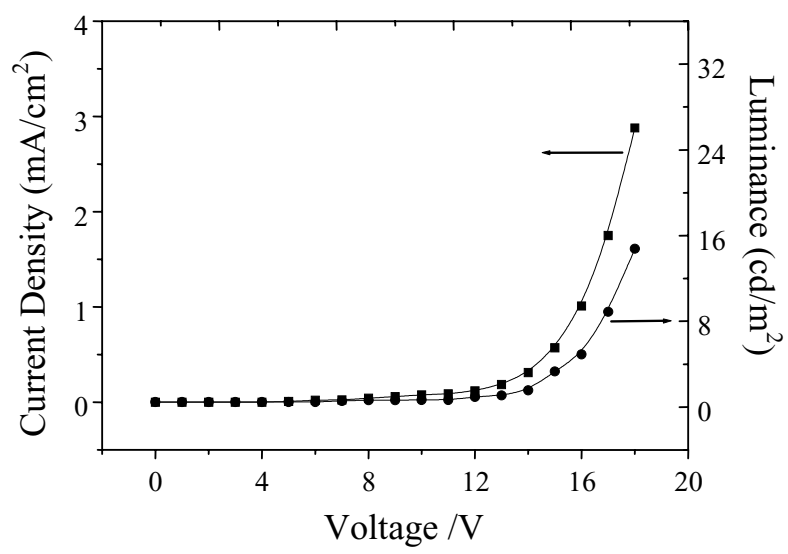

Fig. 5. Luminescence-current density-voltage characteristics of a device with the configuration ITO/CuPc $(12 \mathrm{~nm}) / \mathrm{NPB}(30 \mathrm{~nm}) / \mathrm{NP}-\mathrm{RED} 3$ $(45 \mathrm{~nm}) /$ sodium stearate $(2 \mathrm{~nm}) / \mathrm{Al}(100 \mathrm{~nm})$. this material is hindered. In the same device structure, the organic photovoltaic properties of NP-RED 3 with a $1.1 \mathrm{~V}$ voltage and a $5 \mu \mathrm{A} / \mathrm{cm}^{2}$ current density were observed, when the device was irradiated by the quartz light at $50 \mathrm{~W}$.

Although the OLED performance of the device made by NP-RED 3 was poor relative to that of devices with red-doping method; however, it is still valuable guidance for the materials design started from the currently known structures, specifically for exploring new non-doping red emitters. Till now no any DCM and DCJTB series red emitter can be successfully used to make non-doping red OLED devices $[4,5,10,16]$. Further study directed towards the optimization of the device is being carried out. This includes improving color purity, understanding different performances of the devices with different thickness of the emissive layers, and increasing luminescent efficiency.

\section{Conclusion}

Amino conjugation between the 4-amino-1,8-naphthalimide and the substitutes was observed. The lengthening of the conjugated system and the increase in the electron-donating ability of the substitute result in large red shift of the maximum absorption and emission wavelength of these Schiff base compounds. Some simple 1,8-naphthalimide based compounds were prepared, which emit brilliant red fluorescence in solid films. Concentration quenching effect of fluorescence common for luminescent materials was avoided. NP-RED3 was used as non-doping emissive layer to fabricate electroluminescence devices. The NP-RED3 has an EL peak at $620 \mathrm{~nm}$ with a maximum brightness of $15.5 \mathrm{~cd} / \mathrm{m}^{2}$ and a maximum current density of $2.9 \mathrm{~mA} / \mathrm{cm}^{2}$. Due to synthetic flexibility of this class of materials, work is currently in progress to prepare other 
naphthalimide derivatives with narrower FWHM, higher fluorescence quantum yield, and far-infrared emission.

\section{Acknowledgements}

This research was financially supported by NSFC, Scientific Committee of Shanghai and Education Committee of Shanghai. HT thanks Prof. Chen-Pin Chang (Fu Jen Catholic University/Taiwan) for his measurements of the fluorescent lifetimes.

\section{References}

[1] (a) Y. Hamada, T. Sano, K. Shibata, K. Kuroki, Jpn. J. Appl. Phys. 34 (Part 2) (1995) L824;

(b) J. Kido, W. Ikeda, M. Kimura, K. Nagai, K. Okuyama, Appl. Phys. Lett. 65 (1994) 2124.

[2] (a) G. Sakamoto, C. Adachi, T. Koyama, Y. Taniguchi, C.D. Merritt, H. Murata, Z.H. Kafafi, Appl. Phys. Lett. 75 (1999) 766;

(b) R.C. Kwong, S. Sibley, T. Dubovoy, M. Baldo, S.R. Forrest, M.E. Thompson, Chem. Mater. 11 (1999) 3709.

[3] (a) J. Morgado, F. Cacialli, R. Iqbal, S.C. Moratti, A.B. Holmes, G. Yahioglu, L.R. Milgrom, R.H. Friend, J. Mater. Chem. 11 (2001) 278;

(b) Y. Shirota, J. Mater. Chem. 10 (2000) 1;

(c) Y. Sakakibara, S. Okutsu, T. Enokida, T. Tani, Appl. Phys. Lett. 74 (1999) 2587.

[4] V. Bulovic, A. Shoustikov, M.A. Baldo, E. Bose, V.G. Kozlov, M.E. Thompson, S.R. Forrest, Chem. Phys. Lett. 287 (1998) 455.

[5] C.H. Chen, C.W. Tang, J. Shi, K.P. Klubek, Macromol. Symp. 125 (1998) 49.

[6] B.-J. Jung, C.-B. Yoon, H.-K. Shim, L.-M. Do, T. Zyung, Adv. Funct. Mater. 11 (2001) 430.

[7] X.H. Zhang, B.J. Chen, X.Q. Lin, O.Y. Wong, C.S. Lee, H.L. Wong, S.T. Lee, S.K. Wu, Chem. Mater. 13 (2001) 1565.

[8] Y. Fukuda, T. Watanabe, T. Wakimoto, S. Miyaguchi, M. Tsuchida, Synth. Met. 111-112 (2000) 1.

[9] B.X. Mi, Z.Q. Gao, M.W. Liu, K.Y. Chan, H.L. Kwong, N.B. Wong, C.S. Lee, L.S. Hung, S.T. Lee, J. Mater. Chem. 12 (2002) 1307.

[10] (a) C.H. Chen, C.W. Tang, J. Shi, K.P. Klubek, Thin Solid Films 363 (2000) 327;

(b) V. Bulovic, A. Shoustikov, M.A. Baldo, E. Bose, V.G. Kozlov, M.E. Thompson, S.R. Forrest, Chem. Phys. Lett. 287 (1998) 455; (c) X.T. Tao, S. Miyata, H. Sasabe, G.J. Zhang, T. Wada, M.H. Jiang, Appl. Phys. Lett. 78 (2001) 279;

(d) Z.Y. Xie, L.S. Hung, S.T. Lee, Appl. Phys. Lett. 79 (2001) 1048.

[11] L. Liu, W. Li, Z. Hong, J. Peng, X. Liu, C. Liang, Z. Liu, J. Yu, D. Zhao, Synth. Met. 91 (1997) 267.

[12] M.A. Baldo, D.F. O’Brien, Y. You, A. Shoustikov, S. Stibley, M.E. Thompson, S.R. Forrest, Nature 395 (1998) 151.

[13] D.F. O'Brien, M.A. Baldo, M.E. Thompson, S.R. Forrest, Appl. Phys. Lett. 74 (1999) 442.

[14] M.D. McGehee, T. Bergstedt, C. Zhang, A.P. Saab, M.B. O'Rega, G.C. Bazan, V.I. Sradanov, A.J. Heeger, Adv. Mater. 11 (1999) 1349.
[15] T. Virgili, D.G. Lidzey, D.D.C. Bradley, Adv. Mater. 12 (2000) 58.

[16] C. Adachi, M.A. Baldo, S.R. Forrest, J. Appl. Phys. 87 (2000) 8049.

[17] W.-C. Wu, H.-C. Yeh, L.-H. Chan, C.-T. Chen, Adv. Mater. 14 (2002) 1072.

[18] A.T. Peters, M.J. Bide, Dyes Pigments 6 (1985) 349.

[19] C.J. McAdam, B.H. Robinson, J. Simpson, Organometals 19 (2000) 3644.

[20] J. Gan, H. Tian, Z.H. Wang, K. Chen, J. Hill, P.A. Lane, M.D. Rahn, A.M. Fox, D.D.C. Bradley, J. Organomet. Chem. 645 (2002) 168.

[21] J. Gan, H. Tian, K. Chen, Polym. Adv. Technol. 13 (2002) 584.

[22] H. Tian, J. Gan, K. Chen, J. He, Q.L. Song, X.Y. Hou, J. Mater. Chem. 12 (2002) 1262.

[23] (a) C. Hu, W.H. Zhu, W.Q. Lin, H. Tian, Synth. Met. 102 (1999) 1129 ;

(b) W.H. Zhu, M. Hu, Y.Q. Wu, H. Tian, R.G. Sun, A.J. Epstein, Synth. Met. 119 (2001) 547;

(c) B.J. Chen, Y.Q. Liu, C.S. Lee, G. Yu, S.T. Lee, H.Y. Li, W.A. Gambling, D.B. Zhu, H. Tian, W.H. Zhu, Thin Solid Films 363 (2000) 173 ;

(d) H. Tian, J.H. Su, K.C. Chen, T.C. Wong, Z.Q. Gao, C.S. Lee, S.T. Lee, Opt. Mater. 14 (1) (2000) 91;

(e) W. Ni, J. Su, K. Chen, H. Tian, Chem. Lett. 101 (1997);

(f) H. Tian, W. Zhu, K. Chen, Synth. Met. 91 (1997) 229;

(g) J. Su, T. Xu, K.C. Chen, H. Tian, Synth. Met. 91 (1997) 249;

(h) X. Jiang, Y. Liu, H. Tian, W. Qiu, X. Song, D. Zhu, J. Mater. Chem. 7 (8) (1997) 1395.

[24] F. Cacialli, R.H. Friend, C.M. Bouche, P. Le Barny, H. Facoetti, F. Soyer, P.J. Robin, J. Appl. Phys. 83 (1998) 2343.

[25] H.E. Katz, A.J. Lovinger, J. Johnson, C. Kloc, T. Siegrist, W. Li, Y. Lin, A. Dodabalapur, Nature 404 (2000) 478.

[26] (a) U. Mitschke, P. Bäuerle, J. Mater. Chem. 10 (2000) 1471;

(b) C. Adachi, T. Tsutsui, S. Saito, Appl. Phys. Lett. 55 (1989) 1489;

(c) C. Adachi, T. Tsutsui, S. Saito, Appl. Phys. Lett. 56 (1990) 799.

[27] D. Kolosov, V. Adamovich, P. Djurovich, M.E. Thompson, C. Adachi, J. Am. Chem. Soc. 124 (2002) 9945.

[28] (a) H. Tian, T. Xu, Y.B. Zhao, K.C. Chen, J. Chem. Soc. Perkin Trans. 2 (1999) 545;

(b) H. Tian, W. Ni, J. Su, K. Chen, J. Photochem. Photobiochem. A: Chem. 109 (1997) 213.

[29] A.P. De Silva, T.E. Rice, Chem. Commun. 163 (1999).

[30] A.P. De Silva, D.B. Fox, T.S. Moody, S.M. Weir, Luminescent PET signaling systems, in: V. Ranamurthy, K.S. Schange (Eds.), Optical Sensors and Switches, Marcel Dekker Inc., New York, 2001 (Chapter 2).

[31] M.S. Alexiou, V. Tychopoulos, S. Ghorbanian, J.H.P. Tyman, R.G. Brown, P.I. Brittain, J. Chem. Soc., Perkin Trans. 2 (1990) 837.

[32] B.M. Krasovitskii, B.M. Bolotin, Organic Luminescent Materials, VCH, New York, 1988, pp. 58, 153.

[33] J.-S. Yang, S.-Y. Choiu, K.-L. Liau, J. Am. Chem. Soc. 124 (2002) 2518.

[34] (a) R. Samder, V. Stümpflen, J.H. Wendorff, A. Greiner, Macromolecules 29 (1996) 7705;

(b) I. Janić, M. Kakaš, J. Mol. Struct. 114 (1984) 249.

[35] V. Wintges, P. Valat, J. Kossanyi, L. Biczok, A. Demeter, T. Berces, J. Chem. Soc., Faraday Trans. 90 (3) (1994) 411.

[36] K. Utsugi, S.J. Takano, J. Electrochem. Soc. 139 (1992) 3610.

[37] S. Yin, Z. Xu, W. Huang, F. Zhang, Y. Hou, Y. Wang, X. Xu, Chin. J. Chem. 17 (5) (1999) 462.

[38] E. Martin, R. Weigand, Chem. Phys. Lett. 288 (1998) 52. 